\title{
Impact of poly(vinyl alcohol) adsorption on the surface characteristics of mixed oxide $\mathrm{Mn}_{x} \mathrm{O}_{y}-\mathrm{SiO}_{2}$
}

\author{
M. Wiśniewska ${ }^{1} \cdot$ V. Bogatyrov ${ }^{2} \cdot$ I. Ostolska ${ }^{1} \cdot$ K. Szewczuk-Karpisz ${ }^{1}$ \\ K. Terpiłowski ${ }^{3} \cdot$ A. Nosal-Wiercińska ${ }^{4}$
}

Received: 21 August 2015/Revised: 15 September 2015/ Accepted: 18 September 2015/Published online: 22 September 2015

(C) The Author(s) 2015. This article is published with open access at Springerlink.com

\begin{abstract}
The poly(vinyl alcohol) (PVA) influence on the adsorption and electrokinetic properties of the mixed oxide $\mathrm{Mn}_{x} \mathrm{O}_{y}-\mathrm{SiO}_{2} /$ polymer solution system was examined. Three oxides differing with the $\mathrm{Mn}_{x} \mathrm{O}_{y}$ contents were applied $\left(0.2 ; 1\right.$ and $3 \mathrm{mmol} / \mathrm{g} \mathrm{SiO}_{2}$, respectively). The PVA with the molecular weight $100 \mathrm{kDa}$ was characterized with the acetate groups content equal to $14 \%$. Adsorption, solid surface charge and zeta potential measurements were made as a function of solution $\mathrm{pH}(3-10)$. The obtained results showed that the PVA adsorption amount strongly depends on not only the solution $\mathrm{pH}$, but also manganese oxide content on the mixed oxide surface. The higher solution $\mathrm{pH}$ value (or $\mathrm{Mn}_{x} \mathrm{O}_{y}$ content) is, the higher polymer adsorption is obtained. The PVA addition to the solid suspension causes minimal changes of the mixed oxide surface charge density, whereas the zeta potential of solid particles increases significantly in the polymer presence.
\end{abstract}

M. Wiśniewska

wisniewska@hektor.umcs.lublin.pl

1 Department of Radiochemistry and Colloids Chemistry, Faculty of Chemistry, Maria Curie-Sklodowska University, M. Curie-Sklodowska Sq. 3, 20-031 Lublin, Poland

2 Chuiko Institute of Surface Chemistry, General Naumov Street 17, Kiev 03164, Ukraine

3 Department of Physical Chemistry - Interfacial Phenomena, Faculty of Chemistry, Maria Curie-Sklodowska University, M. Curie-Sklodowska Sq. 3, 20-031 Lublin, Poland

4 Department of Analytical Chemistry and Instrumental Analysis, Faculty of Chemistry, Maria Curie-Sklodowska University, M. Curie-Sklodowska Sq. 3, 20-031 Lublin, Poland
Keywords Mixed oxide $\cdot \mathrm{Mn}_{x} \mathrm{O}_{y}-\mathrm{SiO}_{2} \cdot$ Poly(vinyl alcohol) adsorption $\cdot$ Zeta potential $\cdot$ Solid surface charge density

\section{Introduction}

The application possibilities of metal oxides (including manganese oxides) in various branches of industry and ecology are large. For example $\mathrm{MnO}$ is commonly used as a component of fertilizers and food additives. On the other hand, $\mathrm{MnO}_{2}$ is a component of dry-cell and zinc-carbon batteries. Both solids also find application as inorganic pigments in ceramics and glassmaking. Their other usages include applications in catalysis (synthesis of allyl alcohols, $\mathrm{CO}$ oxidation), paints production, bleaching tallow and textile printing.

A very important aspect from the environmental point of view is the use of metal oxides obtained from removal of hazardous and undesirable substances from wastewaters. Recently manganese oxide coated zeolite was applied to remove $\mathrm{Mn}^{2+}$ from aqueous solutions (Taffarel and Rubio 2010). Manganese dioxide was also used as an adsorbent for phosphate in seawater (Yao and Millero 1996). Copper, cadmium, lead, zinc, iron, selenium and arsenic removal by the use of manganese oxide (both synthetic and natural minerals) was also examined (Kang et al. 2010; Puppa et al. 2013; Ergül et al. 2014; Demirkiran 2015).

However, metal oxides are often characterized by small specific surface area and inadequate stability of their aqueous suspension. In such a case, solid surface modification is necessary. Of great variety of techniques; plasma modification (Kuraica et al. 2003; Punga and Borcia 2013), adsorption of different low- and high-molecular compounds (Chibowski et al. 2010; Nosal-Wiercińska 2012, 2013; Wiśniewska et al. 2013a; Nosal-Wiercińska 2014) and 
Table $1 \mathrm{Mn}_{x} \mathrm{O}_{y}-\mathrm{SiO}_{2}$ mixed oxides characteristics

\begin{tabular}{lllll}
\hline Symbol & $\begin{array}{l}\mathrm{Mn}_{x} \mathrm{O}_{y} \text { content } \\
\left(\mathrm{mmol} \mathrm{Mn}_{x} \mathrm{O}_{y} / \mathrm{g} \mathrm{SiO}_{2}\right)\end{array}$ & $\begin{array}{l}\text { BET surface } \\
\text { area }\left(\mathrm{m}^{2} / \mathrm{g}\right)\end{array}$ & $\begin{array}{l}\text { Pores } \\
\text { volume }\left(\mathrm{cm}^{3} / \mathrm{g}\right)\end{array}$ & $\begin{array}{l}\mathrm{pH}_{\mathrm{pzc}} \mathrm{of} \mathrm{Mn}_{x} \mathrm{O}_{y}-\mathrm{SiO}_{2} / \\
\mathrm{NaCl} \text { systems }\end{array}$ \\
\hline $02 \mathrm{Mn}-\mathrm{SiO}_{2}$ & 0.2 & 306 & 0.934 & 6.88 \\
$1 \mathrm{Mn}-\mathrm{SiO}_{2}$ & 1 & 264 & 1.008 & 7.75 \\
$3 \mathrm{Mn}-\mathrm{SiO}_{2}$ & 3 & 186 & 1.115 & 8.01 \\
\hline
\end{tabular}

synthesis of mixed oxides (Maliyekkal et al. 2006; Wu et al. 2010) acquired the most significant importance. Appropriate modification leads to obtaining solids of the properties desired in various ecological and technological processes (Kaźmierczak et al. 2013; Nowicki et al. 2014, 2015a, b).

Nanocomposites with nanosilica A-380 (Degussa) and grafted manganese oxide were prepared using manganese acetate- $\mathrm{Mn}\left(\mathrm{CH}_{3} \mathrm{COO}\right)_{2} \cdot 4 \mathrm{H}_{2} \mathrm{O}$. The obtained aqueous dispersion was treated at $600{ }^{\circ} \mathrm{C} . \mathrm{Mn}_{x} \mathrm{O}_{y}-\mathrm{SiO}_{2}$ mixed oxides (varying in $\mathrm{Mn}_{x} \mathrm{O}_{y}$ content) obtained in such a way exhibit different surface characteristics and adsorption affinity for macromolecular compounds. They were also characterized by very large surface area. Different structure and surface properties of mixed oxides in comparison to simple oxides can change nature of interactions between the macromolecules and the solid surface. Thus, these substances can be used as effective adsorbents in many technological processes.

In the present study the mechanism of poly(vinyl alcohol) (PVA) adsorption on the surface of $\mathrm{Mn}_{x} \mathrm{O}_{y}-\mathrm{SiO}_{2}$ was investigated. This was done based on the results of measurements: spectrophotometric (determination of the adsorbed amount of the polymer on the solid surface), potentiometric titration (determination of the surface charge density of mixed oxide in the absence and presence of the PVA) and electrokinetic (zeta potential determination of $\mathrm{Mn}_{x} \mathrm{O}_{y}-\mathrm{SiO}_{2}$ particles covered and not with polymeric layers).

As follows from the obtained results the solution $\mathrm{pH}$ (in the range 3-10) affects the adsorption mechanism of PVA on the surface of mixed oxide. The polymer presence also has the effect on the structure of electrical double layers (edl) formed around solid particles.

The PVA was chosen for studies due to its extensive use in many branches of industry. PVA finds a wide application in the production of adhesives, coatings, medicines, paints, paper, oils, fibers and hydrogels (Hassan and Peppas 2000;
Kadajji and Betageri 2011; Karimi and Navidbakhsh 2014). Polyvinyl alcohol is also used in food industry as an agent to retain satisfactory taste, texture and quality of the food (Gupta and Arora 2011).

The monomer of PVA-vinyl alcohol is very unstable and immediately undergoes isomerization to acetaldehyde. For this reason PVA is not prepared by polymerization of the corresponding monomer but in the polymerization process of vinyl acetate. Obtained polyvinyl acetate is converted to the PVA by the hydrolysis of its acetate groups to hydroxyl ones.

\section{Experimental}

\subsection{Materials}

Three samples of mixed oxides, consisting of silica $\left(\mathrm{SiO}_{2}\right)$ and manganese oxide $\left(\mathrm{Mn}_{x} \mathrm{O}_{y}\right)$, were used as adsorbents. All solid samples were prepared in the Institute of Surface Chemistry of the National Academy of Sciences of Ukraine in Kiev. Mixed oxides were characterized by different $\mathrm{Mn}_{x} \mathrm{O}_{y}$ contents, i.e. $0.2 ; 1$ and $3 \mathrm{mmol} / \mathrm{g} \mathrm{SiO}_{2}$ (they were designated as: $02 \mathrm{Mn}-\mathrm{SiO}_{2} ; 1 \mathrm{Mn}-\mathrm{SiO}_{2}$ and $3 \mathrm{Mn}-\mathrm{SiO}_{2}$, respectively). The characteristics of applied solids are given in Table 1. The solid BET surface area was obtained by the nitrogen adsorption-desorption method (Micrometritics ASAP 2405 analyzer).

A PVA-PVA (Fluka) with a weight average molecular weight of $100 \mathrm{kDa}$, was applied as an adsorbate. The hydrolysis degree of PVA was $86 \%$. It means that $14 \%$ of the acetate groups $\left(-\mathrm{OCOCH}_{3}\right)$ do not hydrolyze to hydroxyl $(-\mathrm{OH})$ ones in its production process. PVA is classified as a nonionic polymer, however, its macromolecules comprise a number of acetate groups (as a result of incomplete hydrolysis). These groups undergo ionization with the increasing solution $\mathrm{pH}$, as was schematically shown below.

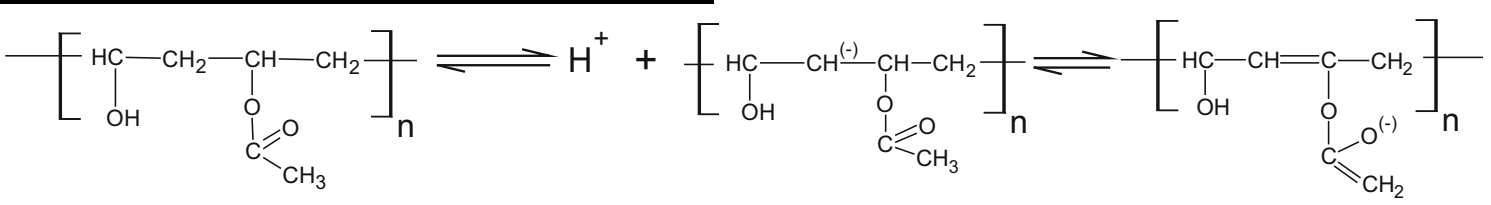


Therefore the applied polymer has negative charges which can interact electrostatically with oppositely charged groups on the solid surface.

All measurements were performed at $25{ }^{\circ} \mathrm{C}$ in the $\mathrm{pH}$ range 3-10, using a solution of $\mathrm{NaCl}$ with the concentration of $0.01 \mathrm{~mol} / \mathrm{dm}^{3}$ as the supporting electrolyte.

\subsection{Methods}

The amount of PVA adsorbed on the surface of the mixed oxides was determined by the static method. The decrease in polymer concentration in the solution after the adsorption process was detected. For this purpose the PVA reaction with $\mathrm{H}_{3} \mathrm{BO}_{3}$ and $\mathrm{I}_{2}$ solutions (Zwick 1965) were applied. As a result, the green colour of the PVA solution of varying intensity (depending on the polymer concentration) was obtained. Absorbancies of these solutions were measured using a UV/VIS spectrophotometer Cary 100 (Varian).

First, three series of PVA solutions were prepared (seven solutions in each). The polymer concentrations for each series were: $30,50,70,100,200,300$ and $400 \mathrm{ppm}$. Then the appropriate $\mathrm{pH}(3,6,9 \pm 0.1)$ was adjusted. The $\mathrm{pH}$ values of the examined system were adjusted using a pH-meter PHM 240 (Radiometer) with the accuracy \pm 0.1 .

After $15 \mathrm{~min}$ from the addition of appropriate reagents (causing green colour of the solution), absorbancies were measured at the wavelength $682 \mathrm{~nm}$. These measurements were performed using quartz cuvettes. Based on these results calibration curves, showing the absorbance versus the concentration of the polymer solution, were prepared.

The PVA concentration in the solution was determined in an analogous way. To the polymer solutions of the concentrations ranging from 30 to $400 \mathrm{ppm}, 0.005 \mathrm{~g}$ of the solid was added and the appropriate $\mathrm{pH}$ was adjusted. The adsorption process was carried out under the conditions of continuous shaking for approx. $24 \mathrm{~h}$ [using a shaker Uni$\max 1010$ (Heidolph) with the attached heating module (type Incubator 1000)]. It should be noted that adsorption equilibrium in examined systems was achieved after about $6 \mathrm{~h}$. Then, the samples were centrifuged [centrifuge type 223e (MPW Med. Instruments)] and the concentration of PVA in the solution was determined (using respective calibration curves). From the difference of polymer concentration before and after adsorption, the PVA amount adsorbed on the mixed oxide surface was determined.

For the potentiometric titration, a set consisting of: thermostated Teflon vessel, glass and calomel electrodes (Beckman Instruments), pH-meter PHM 240 (Radiometer), laboratory mixers, thermostat RE 204 (Lauda), automatic microburette Dosimat 765 (Metrohm) and computer, was applied. Titrations were performed using the software "titr_v3" authored by prof. W. Janusz. This program enables solid surface charge density calculation and oxide $\mathrm{pH}_{\mathrm{pzc}}$ (point of zero charge) determination.

Potentiometric titration started with the preparation of $50 \mathrm{~cm}^{3}$ of supporting electrolyte in the thermostatted Teflon vessel. To obtain $\mathrm{pH}$ in the range $3-3.5,0.2 \mathrm{~cm}^{3} \mathrm{HCl}$ (with the concentration $0.1 \mathrm{~mol} / \mathrm{dm}^{3}$ ) was added. After equilibrium was reached, the examined system was titrated with a $\mathrm{NaOH}$ solution (with the concentration $0.1 \mathrm{~mol} / \mathrm{dm}^{3}$ ). As a result the dependence of the titrated solution $\mathrm{pH}$ as a function of added base volume (reference or electrolyte curve) was obtained. Identical potentiometric titration was performed in the systems: $\mathrm{Mn}_{x} \mathrm{O}_{y}-\mathrm{SiO}_{2}$ /electrolyte solution and $\mathrm{Mn}_{x} \mathrm{O}_{y}-\mathrm{SiO}_{2} / \mathrm{PVA}$ solution. The masses of applied solids were: $0.065 \mathrm{~g}$ for $02 \mathrm{Mn}-\mathrm{SiO}_{2} ; 0.076 \mathrm{~g}$ for $1 \mathrm{Mn}-\mathrm{SiO}_{2}$ and $0.107 \mathrm{~g}$ for $3 \mathrm{Mn}-\mathrm{SiO}_{2}$. The polymer concentration in the system was $100 \mathrm{ppm}$.

The zeta potential of mixed oxides particles (without and with PVA adsorption layers) was measured using a Zetasizer Nano ZS (Malvern Instruments). Suspensions were prepared by adding $0.01 \mathrm{~g}$ of the solid to $50 \mathrm{~cm}^{3}$ of the electrolyte or polymer solution (100 ppm). After the suspension sonication for $5 \mathrm{~min}$ [ultrasonicator XL 2020 (Misonix)], the solution was poured into seven $10 \mathrm{~cm}^{3}$ Erlenmayer flasks. In each of them the appropriate $\mathrm{pH}$ value was adjusted (i.e. $3 ; 4 ; 5 ; 6$; $7 ; 8 ; 9$, respectively). The $\zeta$ potential of such prepared suspension was measured using the dip cell. Before each experiment the cell was rinsed twice with the suspension under investigation. Zeta potential was calculated using the special computer program making conversion of the electrophoretic mobility of particles in the zeta potential. For this purpose the Smoluchowski equation was applied. The final value of the electrokinetic potential was the average of five measurements.

\section{Results and Discussion}

Figure 1 presents the adsorption isotherms of PVA on the surface of mixed oxide $1 \mathrm{Mn}-\mathrm{SiO}_{2}$ for different solution $\mathrm{pH}$. As can be seen, PVA adsorption increases with the $\mathrm{pH}$ rise. The similar dependencies were obtained for two other examined oxides (i.e. $02 \mathrm{Mn}-\mathrm{SiO}_{2}$ and $3 \mathrm{Mn}-\mathrm{SiO}_{2}$ ). On the other hand, Fig. 2 shows the adsorbed amounts of PVA on the surface of mixed oxide for different contents of Mn. The increase in the manganese oxide content on the mixed oxide surface results in higher adsorption of polyalcohol.

Such adsorption behaviour of the polymer is related to the conformation of its macromolecules under specified $\mathrm{pH}$ conditions. As mentioned earlier, the chains of PVA contain a certain number of acetate groups (14\%), which are the source of the negative charge of the polymer molecules. Even such a relatively small part of these groups affects the structure of the PVA adsorption layer. Our previous study 


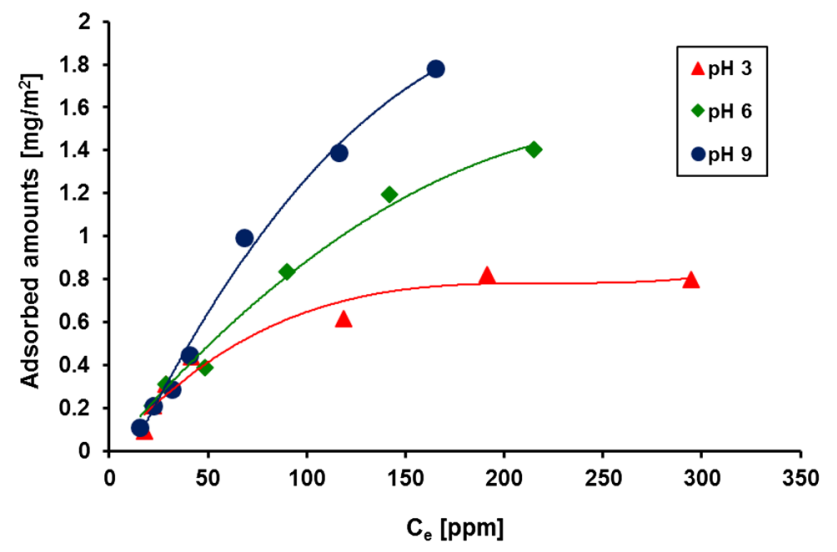

Fig. 1 Adsorption isotherms of poly(vinyl alcohol) on the surface of mixed oxide $1 \mathrm{Mn}-\mathrm{SiO}_{2}$ for different solution $\mathrm{pH}$

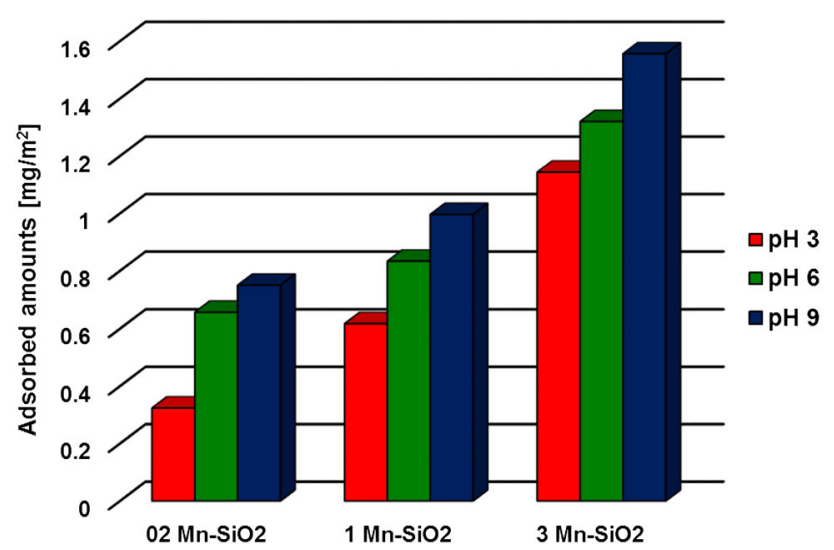

Fig. 2 Adsorbed amounts of poly(vinyl alcohol) on the surface of mixed oxide for different content of Mn for different solution $\mathrm{pH}$, $\mathrm{C}_{\mathrm{PVA}}=200 \mathrm{ppm}$

indicated that the acetate groups play an essential role in the PVA adsorption - the increase of the number of these groups in the polymeric chains led to higher adsorption levels (Chibowski et al. 2000). Contribution of charged acetate groups rises as the solution $\mathrm{pH}$ increases. It results in larger extension of polymer chains due to the electrostatic repulsion of negative charges located along polymeric chains. The degree of the polymer macromolecules development directly affects the amount of PVA adsorbed on the $\mathrm{Mn}_{x} \mathrm{O}_{y}-\mathrm{SiO}_{2}$ surface.

At pH 3 macromolecular compound chains adopt the least developed conformation. They form loop and tail structures of small length on the solid surface. Such flat arrangement of the adsorbed macromolecule results in the occupation of large surface area of the mixed oxide. This leads to the blockade of other PVA chains access to the solid active sites. It is worth noting that under these conditions mixed oxide is positively charged $\left(\mathrm{pH}_{\mathrm{pzc}}\right.$ in the range 6.88-8.01, Table 1). Thus, there is electrostatic attraction between the $\mathrm{Mn}_{x} \mathrm{O}_{y}-\mathrm{SiO}_{2}$ surface and the PVA macromolecules (slightly negatively charged). This phenomenon contributes also to the adoption of flatter structure of the polymer chains in surface layer. Such adsorption mechanism causes obtaining the lowest level of PVA adsorption at the smallest examined $\mathrm{pH}$ value.

Intermediate values of the PVA adsorbed amounts were obtained at $\mathrm{pH}$ 6. This is due to a larger content of charged segments with the acetate groups which mutually repeal each other. As a result, the polymer macromolecules assume more stretched conformation than in the solution of $\mathrm{pH}$ 3. The structure of the polymeric adsorption layer formed on the solid surface is characterized by a greater length of the loop and tail fragments of PVA chains. The adsorbed PVA macromolecules occupy a smaller surface area than that at $\mathrm{pH} 3$. This allows greater packing density of the polymeric layer to be formed at the solid-liquid interface, resulting in the observed adsorption increase. Additionally, at $\mathrm{pH} 6$ the electrostatic adsorbent-adsorbate attraction is weaker than at $\mathrm{pH} 3$ (lower positive charge of the mixed oxide surface). This also favours formation of the thicker layers by PVA chains on the solid surface.

At $\mathrm{pH} 9$, practically all the acetate groups of the polymer macromolecules are endowed with a negative charge. As a result, electrostatic repulsion of charged segments is the strongest. These interactions lead to the greatest development of the polyalcohol chains. On the other hand, the solid surface is also negatively charged. This additionally intensifies the degree of PVA macromolecules stretching. Polymeric molecules possessing such a conformation can be adsorbed in large amounts on the solid surface. At $\mathrm{pH} 9$ polymer tails and loops are the longest and PVA adsorption is the highest.

The obtained results proved that adsorbent-adsorbate electrostatic repulsion does not prevent adsorption of PVA on the surface of the mixed oxide. On the contrary, it promotes the formation of a specific conformation of the adsorbed macromolecule that provides the highest level of adsorption. Under such unfavourable electrostatic conditions, PVA segments are directly bounded with the solid surface active sites through hydrogen bonds (KasprzykHordern 2004). These bonds can be formed between all types of surface groups (charged: $-\mathrm{MO}^{-},-\mathrm{MOH}_{2}{ }^{+}$and uncharged $-\mathrm{MOH}$, where $\mathrm{M}$ is atom of $\mathrm{Si}$ or $\mathrm{Mn}$ ) and functional groups of polymer-hydroxyl and acetate (both neutral and ionized).

It was demonstrated that the PVA adsorption on the surface of the mixed oxide depends strongly on the manganese oxide content in the solid structure (Fig. 2). The smallest PVA adsorbed amount is observed on the surface of the mixed oxide $02 \mathrm{Mn}-\mathrm{SiO}_{2}$ and the highest-for $3 \mathrm{Mn}-\mathrm{SiO}_{2}$. For example at pH 9 over twice higher PVA adsorption occurs on the $3 \mathrm{Mn}-\mathrm{SiO}_{2}$ surface in comparison 
to that on the $02 \mathrm{Mn}-\mathrm{SiO}_{2}$ surface. The analogous tendency is observed for all examined solution $\mathrm{pH}$ values.

The increase in PVA adsorption with the increase of manganese content on the surface of the mixed oxide proves that solid active sites containing Mn atoms are mainly responsible for polymer binding. The role of active sites containing $\mathrm{Si}$ atoms in this process must be considerably smaller. In aqueous solution metal atoms undergo hydroxylation. Formed hydroxyl groups are involved in hydrogen bond formation between the $\mathrm{Mn}_{x} \mathrm{O}_{y}-\mathrm{SiO}_{2}$ surface and poly(vinyl alcohol macromolecules). Moreover, hydroxyl groups on the solid surface are amphoteric and can connect or disconnect proton. This leads to the formation of electrical charge which can interact with the ionized groups of PVA. A higher content of metal in the structure of the mixed oxide is equivalent to a greater number of possible interactions with the adsorbate molecules. As a consequence, higher PVA adsorption occurs on the surface of the mixed oxide $\mathrm{Mn}_{x} \mathrm{O}_{y}-$ $\mathrm{SiO}_{2}$ characterized by the greatest $\mathrm{Mn}$ content.

Figures 3 and 4 present the results of potentiometric titrations in the mixed oxide/solution systems as dependencies of the solid surface charge density $\left(\sigma_{0}\right)$ versus solution $\mathrm{pH}$. The influence of manganese oxide content on the surface charge density of $\mathrm{Mn}_{x} \mathrm{O}_{y}-\mathrm{SiO}_{2}$ mixed oxides without polymer is shown in Fig. 3. As can be seen, the point of zero charge of the $\mathrm{Mn}_{x} \mathrm{O}_{y}-\mathrm{SiO}_{2}$ surface is in the range of 6.88-8.01. The higher content of $\mathrm{Mn}$ in the surface structure of the solid indicated that the greater value of $\mathrm{pH}_{\mathrm{pzc}}$ is reached. This is probably caused by the formation of a greater number of positively charged $-\mathrm{MnOH}_{2}{ }^{+}$surface groups. Evidence of this is also increase in positive value of $\sigma_{0}$ in the $\mathrm{pH}$ range 4-8 with the rise of manganese oxide content. It is worth noting that the addition of manganese on the silica surface leads to modification of the solid characteristics. This manifests in a noticeable shift of $\mathrm{pH}_{\mathrm{pzc}}$ position (towards the more alkaline $\mathrm{pH}$ ) in relation to that of $\mathrm{SiO}_{2}$ whose value is about 3 (Wiśniewska 2012a, b, 2013b).

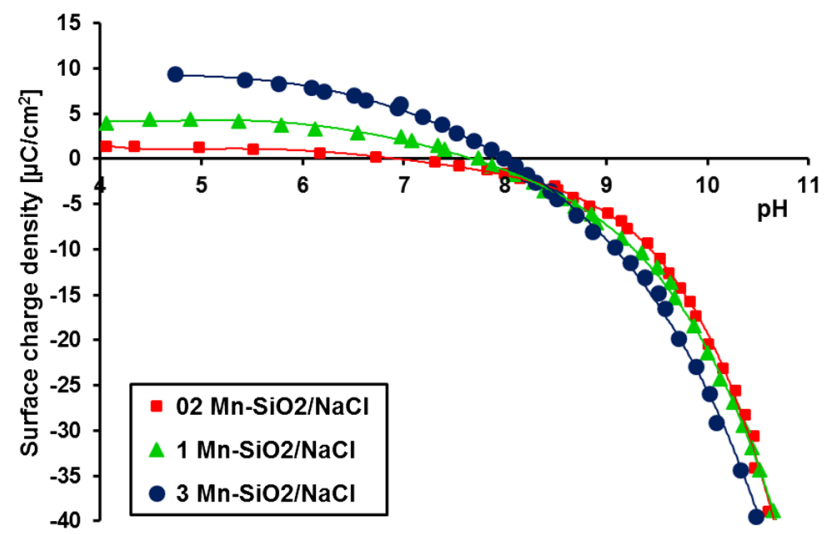

Fig. 3 Surface charge density of $\mathrm{Mn}_{x} \mathrm{O}_{y}-\mathrm{SiO}_{2}$ mixed oxides without polymer

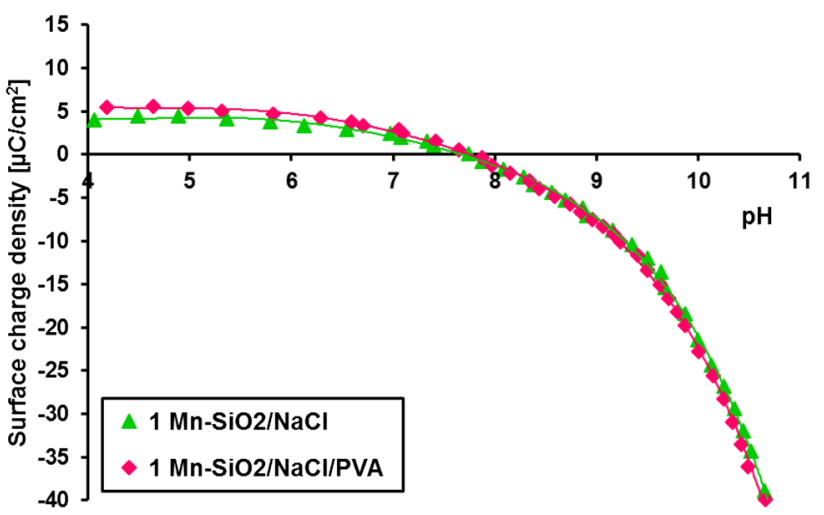

Fig. 4 Surface charge density of $1 \mathrm{Mn}-\mathrm{SiO}_{2}$ mixed oxide without and with poly(vinyl alcohol)

The analysis of the dependencies in Fig. 4 leads to the conclusion that adsorption of PVA on the $1 \mathrm{Mn}-\mathrm{SiO}_{2}$ surface practically does not change the surface charge of the solid. The similar data are obtained for the other examined systems. Such behaviour occurs in the case of nonionic polymers and confirms that hydrogen bonds are responsible for the PVA chains adsorption on the $\mathrm{Mn}_{x} \mathrm{O}_{y}-\mathrm{SiO}_{2}$ surface. Although PVA contains ionizable acetate groups, their content of in the PVA macromolecules (14\%) is insufficient to cause noticeable changes in $\sigma_{0}$ of the adsorbent. It should be also added that negative charge of poly(vinyl alcohol chains) is due to the existence of resonant structure of polymer macromolecule and migration of partial negative charge from the $-\mathrm{CH}_{2}{ }^{-}$groups located at $\alpha$ positions relative to the acetate groups to carbonyl oxygen of the acetate group (and conversely). This dispersion of negative charge on various chain fragments makes its influence on the solid surface charge density minimal.

Next to the solid surface charge, the electrokinetic potential $(\zeta)$ is an equally important parameter characterizing the structure of the edl formed at the mixed oxide/solution interface. The results of zeta potential measurements are given in Figs. 5, 6, and 7. The analysis of dependencies obtained for the mixed oxides in the supporting electrolyte solution (without PVA) indicates that $\zeta$ potential is negative in the whole range of studied $\mathrm{pH}$ and its absolute values increase with the $\mathrm{pH}$ rise. This means that in the slipping plane within edl, negative ions of supporting electrolyte $\left(\mathrm{Cl}^{-}\right)$predominate. Very interesting is the influence of manganese oxide content on the zeta potential of $\mathrm{Mn}_{x} \mathrm{O}_{y}-\mathrm{SiO}_{2}$ mixed oxides particles without polymer (Fig. 5). The smallest absolute values of electrokinetic potential are obtained for the $1 \mathrm{Mn}-\mathrm{SiO}_{2}$ system, whereas the greatest ones for the $3 \mathrm{Mn}-\mathrm{SiO}_{2}$ system. The zeta potentials characterizing $02 \mathrm{Mn}-\mathrm{SiO}_{2}$ (with the smallest content of manganese oxide) assume intermediate values. The highest Mn content in the solid structure (and 


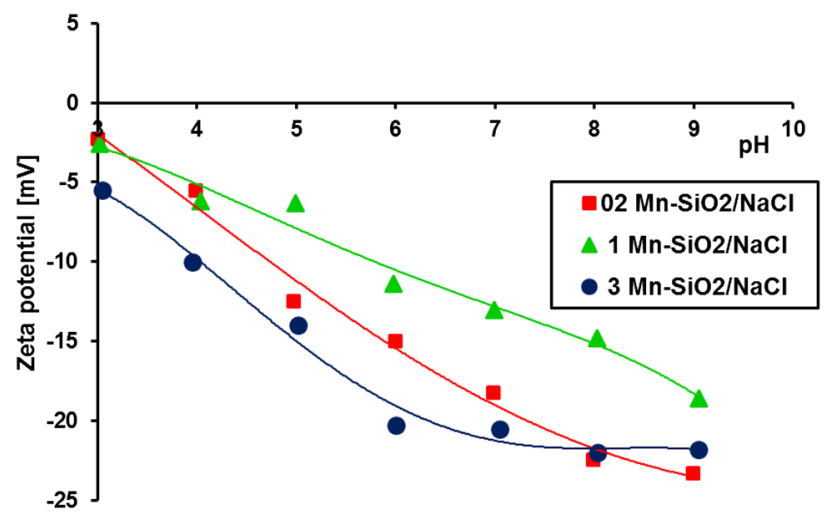

Fig. 5 Zeta potential of $\mathrm{Mn}_{x} \mathrm{O}_{y}-\mathrm{SiO}_{2}$ mixed oxides particles without poly(vinyl alcohol)

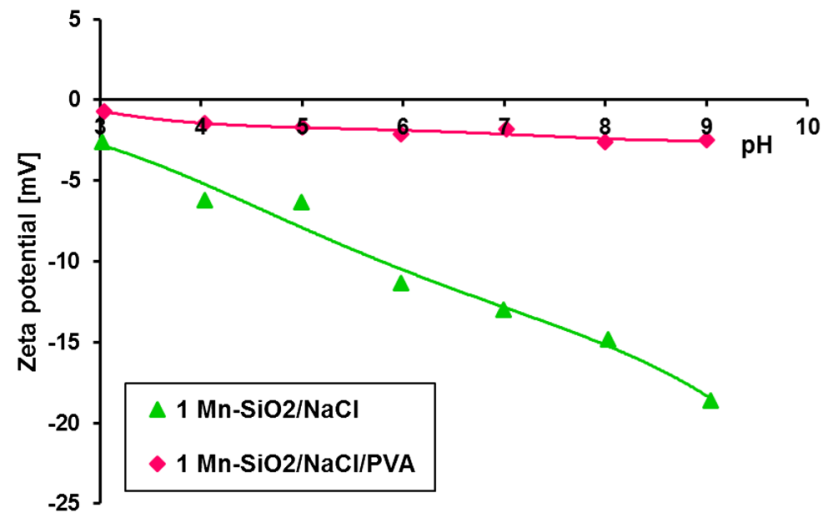

Fig. 6 Zeta potential of $1 \mathrm{Mn}-\mathrm{SiO}_{2}$ mixed oxide particles without and with poly(vinyl alcohol)

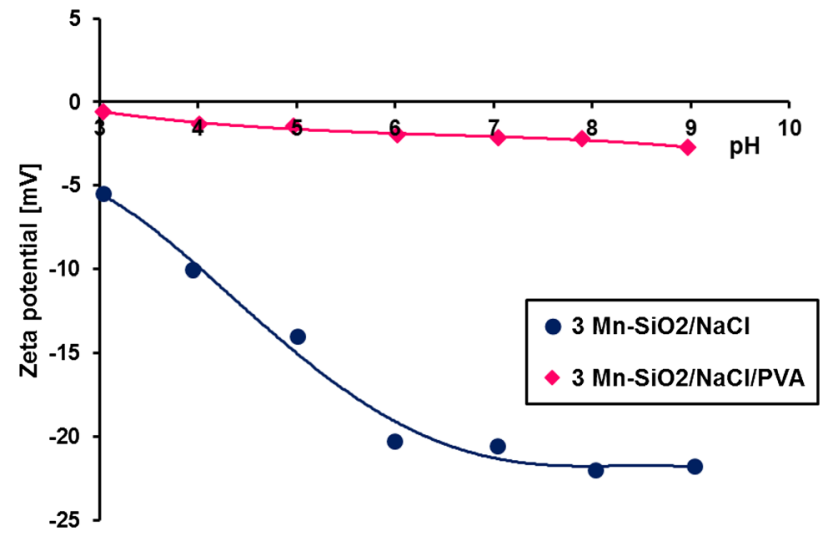

Fig. 7 Zeta potential of $3 \mathrm{Mn}-\mathrm{SiO}_{2}$ mixed oxide particles without and with poly(vinyl alcohol)

thus a larger content of $-\mathrm{MnOH}_{2}{ }^{+}$surface groups) requires attachment of a greater number of supporting electrolyte counter-ions in the Stern layer of edl.

The addition of PVA causes a decrease in the absolute value of the electrokinetic potential, whereas its sign remains negative. This decrease is the smallest for the $02 \mathrm{Mn}-\mathrm{SiO}_{2}$ system (Fig. 6) and the greatest for the $3 \mathrm{Mn}-$ $\mathrm{SiO}_{2}$ system (Fig. 7). Three different effects can be responsible for the changes in the zeta potential in the presence of polymer. There are: (1) the shift of the slipping plane from the solid surface due to polymeric adsorption layer formation, (2) the presence of the charges coming from the PVA acetate groups in the by-surface layer of the solution, (3) the displacement of the counter-ions from the slipping plane layer caused by the polymer binding with the oxide surface (Vincent 1974). In the summary, these effects overlap and give final values of zeta potential of the solid suspensions containing PVA. The main effect in the examined $\mathrm{Mn}_{x} \mathrm{O}_{y}-\mathrm{SiO}_{2} / \mathrm{NaCl} / \mathrm{PVA}$ systems seems to be displacement of the supporting electrolyte ions by the loop and tail structures of the adsorbed polymer chains from the surface layer to the slipping plane. It changes composition of the electrical double layer in relation to simple electrolyte ions. On the other hand, the presence of negatively charged acetate groups in the polymeric chains and the slipping plane shift due to the polymer adsorption can also affect the zeta potential of the examined systems.

\section{Conclusions}

The amount of PVA adsorbed on the $\mathrm{Mn}_{x} \mathrm{O}_{y}-\mathrm{SiO}_{2}$ surface depends on the solution $\mathrm{pH}$, the content of manganese oxide in the structure of the solid and the ionization degree of the acetate groups in the polymer macromolecules. The specific conformation of the adsorbed PVA macromolecules assumed under given $\mathrm{pH}$ conditions is responsible for PVA adsorption increase with the $\mathrm{pH}$ rise. At $\mathrm{pH} 3$ the adsorbing PVA macromolecules are more coiled (low ionization of acetate groups in the polymeric chains) and form rather flat structure on the solid surface (slight solidPVA electrostatic attraction). This leads to the blockade of solid active sites by polymeric coils and the lowest PVA adsorption level. On the contrary, at $\mathrm{pH} 9$ a thicker adsorption layer is formed due to solid-polymer repulsion and a greater extent of adsorbing macromolecules (total ionization of their acetate groups). As a result, greater packing of the adsorbed PVA chains on the surface unit is possible leading to the increase of PVA adsorption. The higher is the manganese content on the mixed oxide surface, the larger is the amount of adsorbed polymer. It is related to a greater number of possible connections between the polymer segments and the solid surface group containing $\mathrm{Mn}$ atoms.

The modification of silica surface with manganese oxide results in change of its properties. The value of their $\mathrm{pH}_{\mathrm{pzc}}$ points increases from 6.88 to 8.01 with the increasing $\mathrm{Mn}$ content. Adsorption of PVA minimally affects the surface 
charge density of mixed oxides (hydrogen bridges are mainly responsible for PVA adsorption). The zeta potential of mixed oxide particles is negative in the whole range of studied $\mathrm{pH}$. The PVA addition results in significant increase of the zeta potential values in all examined $\mathrm{Mn}_{x} \mathrm{O}_{y}-$ $\mathrm{SiO}_{2}$ systems in relation to the suspensions without polymer.

Acknowledgments The research leading to these results has received funding from the People Programme (Marie Curie Actions) of the European Union's Seventh Framework Programme FP7/20072013/under REA Grant agreement nº PIRSES-GA-2013-612484.

Open Access This article is distributed under the terms of the Creative Commons Attribution 4.0 International License (http://crea tivecommons.org/licenses/by/4.0/), which permits unrestricted use, distribution, and reproduction in any medium, provided you give appropriate credit to the original author(s) and the source, provide a link to the Creative Commons license, and indicate if changes were made.

\section{References}

Chibowski, S., Paszkiewicz, M., Krupa, M.: Investigation of the influence of the polyvinyl alcohol adsorption on the electrical properties of $\mathrm{Al}_{2} \mathrm{O}_{3}$-solution interface, thickness of the adsorption layers of PVA. Powder Tech. 107, 251-255 (2000)

Chibowski, S., Wiśniewska, M., Urban, T.: Influence of solution $\mathrm{pH}$ on stability of aluminum oxide suspension in presence of polyacrylic acid. Adsorption 16, 321-332 (2010)

Demirkiran, N.: Copper adsorption by natural manganese dioxide. Trans. Nonferr. Met. Soc. China 25, 647-653 (2015)

Ergül, B., Bektas, N., Öncel, M.S.: The use of manganese oxide minerals for the removal arsenic and selenium anions from aqueous solutions. Energy Environ. Eng. 2, 103-112 (2014)

Gupta, A.P., Arora, G.: Preparation and characterization of guar-gum/ polyvinylalcohol blend films. J. Mat. Sci. Eng. B 1, 28-33 (2011)

Hassan, C.M., Peppas, N.A.: Structure and applications of poly(vinyl alcohol) hydrogels produced by conventional crosslinking or by freezing/thawing methods. Adv. Polym. Sci. 153, 37-65 (2000)

Kadajji, V.G., Betageri, G.V.: Water soluble polymers for pharmaceutical applications. Polymers 3, 1972-2009 (2011)

Kang, D.H., Schwab, A.P., Johnston, C.T., Banks, M.K.: Adsorption of iron cyanide complexes onto clay minerals, manganese oxide, and soil. J. Environ. Sci. Health. A 45, 1391-1396 (2010)

Karimi, A., Navidbakhsh, M.: Mechanical properties of PVA material for tissue engineering applications. Mater. Technol. 29, 90-100 (2014)

Kasprzyk-Hordern, B.: Chemistry of alumina, reactions in aqueous solution and its application in water treatment. Adv. Colloid Interface Sci. 110, 19-48 (2004)

Kaźmierczak, J., Nowicki, P., Pietrzak, R.: Sorption properties of activated carbons obtained from corn cobs by chemical and physical activation. Adsorption 19, 273-281 (2013)

Kuraica, M.M., Astashynski, V.M., Dojcinovic, I.P., Puric, J.: Modification of solid surface by a compression plasma flow. Phys. Laser Cryst. 126, 245-255 (2003)
Maliyekkal, S.M., Sharma, A.K., Philip, L.: Manganese-oxide-coated alumina: a promising sorbent for defluoridation of water. Water Res. 40, 3497-3506 (2006)

Nosal-Wiercińska A.: Intermolecular interactions in systems containing $\mathrm{Bi}(\mathrm{III})-\mathrm{ClO}_{4}^{-}-\mathrm{H}_{2} \mathrm{O}$-selected amino acids in the aspect of catalysis of $\mathrm{Bi}(\mathrm{III})$ electroreduction. Electroanalysis 26, 1013-1023 (2014)

Nosal-Wiercińska, A.: The role of active complexes in the multistep process of $\mathrm{Bi}(\mathrm{III})$ ion electroreduction in chlorate (VII) solutions with varied water activity in the presence of cystine. Electrochim. Acta 92, 397-403 (2013)

Nosal-Wiercińska, A.: Electrochemical and thermodynamic study of the electroreduction of $\mathrm{Bi}(\mathrm{III})$ ions in the presence of cystine in solutions of different water activity. J. Electroanal. Chem. 681, 103-108 (2012)

Nowicki, P., Skibiszewska, P., Pietrzak, R.: Hydrogen sulphide removal on carbonaceous adsorbents prepared from coffee industry waste materials. Chem. Eng. J. 248, 208-215 (2014)

Nowicki, P., Kaźmierczak, J., Pietrzak, R.: Comparison of physicochemical and sorption properties of activated carbons prepared by physical and chemical activation of cherry stones. Powder Technol. 269, 312-319 (2015a)

Nowicki, P., Kaźmierczak, J., Sawicka, K., Pietrzak, R.: Nitrogenenriched activated carbons prepared by the activation of coniferous tree sawdust and their application in the removal of nitrogen dioxide. Int. J. Environ. Sci. Technol. 12, 2233-2244 (2015b)

Punga, I.L., Borcia, G.: Surface modification and stability of polymers treated by atmospheric-pressure, helium plasma. J. Adv. Res. Phys. 4, 011305 (2013)

Puppa, L.D., Komarek, M., Bordas, F., Bollinger, J.C., Joussein, E.: Adsorption of copper, cadmium, lead and zinc onto a synthetic manganese oxide. J. Colloid Interface Sci. 399, 99-106 (2013)

Taffarel, S.R., Rubio, J.: Removal of $\mathrm{Mn}^{2+}$ from aqueous solution by manganese oxide coated zeolite. Min. Eng. 23, 1131-1138 (2010)

Vincent, B.: The effect of adsorbed polymers on dispersion stability. Adv. Colloid Interface Sci. 4, 193-277 (1974)

Wiśniewska, M., Nosal Wiercińska, A., Dąbrowska, I., SzewczukKarpisz, K.: Effect of the solid pore size on the structure of polymer film at themetal oxide/polyacrylic acid solution interface - temperature impact. Microporous Mesoporous Mater. 175, 92-98 (2013a)

Wiśniewska, M., Szewczuk-Karpisz, K., Ostolska, I.: Temperature effect on the adsorption equilibrium at the silica - polyethylene glycol solution interface. Fluid Ph. Equilb. 360, 10-15 (2013b)

Wiśniewska, M.: Temperature effects on the adsorption polyvinyl alcohol on silica. Cent. Eur. J. Chem. 10, 1236-1244 (2012a)

Wiśniewska, M.: The temperature effect on the adsorption mechanism of polyacrylamide on the silica surface and its stability. Appl. Surf. Sci. 258, 3094-3101 (2012b)

Wu, X., Lin, F., Xu, H., Weng, D.: Effects of adsorbed and gaseous $\mathrm{NO}_{x}$ species on catalytic oxidation of diesel soot with $\mathrm{MnO}_{\mathrm{x}}-$ $\mathrm{CeO}_{2}$ mixed oxides. Appl. Cat. B. 96, 101-109 (2010)

Yao, W., Millero, F.J.: Adsorption of phosphate on manganese dioxide in seawater. Environ. Sci. Technol. 30, 536-541 (1996)

Zwick, M.M.: Poly(vinyl alcohol)-iodine complexes. J. Appl. Polym. Sci. 9, 2393-2424 (1965) 